\title{
Músicas locales, construcción de paz y post-conflicto: el caso de Libertad (Sucre) ${ }^{1}$
}

\author{
Juan Sebastián Rojas/ Universidad El Bosque
}

Este artículo explora los roles qué han jugado la música y otras prácticas culturales y expresiones populares del corregimiento de Libertad, en San Onofre (Sucre), como parte del Plan Integral de Reparación Colectiva (PIRC) implementado por la Unidad para la Atención y Reparación Integral a las Víctimas (UARIV), institución del Gobierno nacional, en esta comunidad desde el inicio de su diseño en 2007. Aquí analizo una situación en la que víctimas del conflicto armado han utilizado expresiones artísticas tradicionales adaptadas de manera consciente y específica con el objetivo de adelantar procesos locales de construcción de paz. Algunas iniciativas de estos líderes y músicos comunitarios - tales como el apoyo a las prácticas de bullerengue, el desarrollo de nuevas músicas locales y la revitalización de los velorios tradicionales afrocolombianos - se han incluido en las acciones del PIRC y han encontrado apoyo adicional a través de diversas ONG. Este plan de reparación, el cual incluye medidas en ámbitos desde la infraestructura hasta la educación, se ha convertido en la carta de navegación para las organizaciones locales que buscan construir iniciativas de desarrollo comunitario y facilitar la reparación a los habitantes de esta población por lo ocurrido durante la ocupación. Basado en una investigación etnográfica de cinco años en Libertad, aquí examino las maneras en que las prácticas musicales colectivas en esta comunidad han sido utilizadas como estrategia de rehabilitación comunitaria en este escenario de post-conflicto.

Desde el inicio de los procesos de reparación colectiva se ha discutido a nivel local la idea de la revitalización de las músicas tradicionales, en parte por la creencia local de que la música ha sido usada en el pasado, y también puede serlo en el futuro, para facilitar contextos de cohesión social. Esta creencia local está basada en las maneras en que las músicas locales empoderan a los miembros del colectivo, ayudan a reconstruir redes de cooperación y generan marcos para la expresión creativa y no-violenta, lo que resulta en la generación de suficientes rasgos comunes, afectos compartidos e intereses colectivos entre los miembros del grupo social, generando fortalecimiento de los vínculos. Como se expondrá a continuación, las prácticas musicales colectivas en el pueblo de Libertad están jugando un papel importante en la reintegración social de la comunidad hoy día. Estos proyectos han tenido impacto positivo en jóvenes miembros de la comunidad pertenecientes a diversos grupos locales, no sólo por las acciones de recuperación de prácticas culturales tradicionales, sino también como parte de un proceso más amplio de transformación de conflictos y restauración del tejido social a nivel local.

En su artículo, donde teorizan sobre la idea del "sentido de comunidad" (sense of community), David McMillan y David Chavis caracterizan el "tejido social" (social fabric) como un término usado para representar la "fuerza en las relaciones interpersonales" en una comunidad, lo que puede evaluarse a partir de la observación de un espectro diverso de interacciones entre vecinos (McMillan y Chavis 1986: 7, traducción mía). Un tejido social fuerte es la consecuencia de un sentido de comunidad desarrollado; y un sentido de comunidad desarrollado, para McMillan y Chavis, está determinado por cuatro criterios: la membresía y el sentido de pertenencia; la influencia y el sentido de importar dentro del grupo; la percepción de integración y de satisfacción de necesidades; y las conexiones emocionales compartidas $(1986,9)$. Así, el sentido de comunidad puede ser definido como:

un sentimiento que los miembros tienen de pertenecer, un sentimiento de que importan los unos a los otros y al grupo, y una fe compartida en que las necesidades de los miembros van a ser resueltas a través de su compromiso de estar juntos. (McMillan 1976; citado en McMillan y Chavis 1986, 9)

En el corregimiento de Libertad, los líderes locales creen que esta idea del sentido de comunidad puede ser fácilmente construida a través de la música y el performance.

De esta forma, voy a analizar cuatro factores que ayudan a explicar la relación dinámica que se da entre la recuperación de prácticas culturales tradicionales y la rehabilitación comunitaria en contextos de post-conflicto (en el caso de Libertad): 1) las funciones socioculturales e históricas de las músicas festivas y participativas en las sociedades afrocolombianas, incluyendo Libertad, pues la gente las ha usado como herramienta de resistencia, transformación y construcción comunitaria desde inicios del periodo colonial; 2) la resiliencia de un grupo de músicos y artistas liberteños, quienes administran sus recursos culturales con consciencia política para crear obras usando, no sólo las tradiciones musicales locales, sino también expresiones contemporáneas como el hip-hop; 3) la existencia de capital social multinivel asociado con colectivos musicales locales, diversas organizaciones liberteñas, programas gubernamentales y diversas 
ONG; y 4) la implementación de programas institucionales en Libertad que usan, en mayor o menor medida, metodologías participativas que facilitan que líderes locales tomen decisiones para desarrollar acciones específicas que resuelvan necesidades locales.

Esta investigación está basada en teorías de la construcción de paz y la transformación social, así como en estudios etnomusicológicos recientes sobre música y conflicto (O'Connell y Castelo-Branco 2010, McDonald 2013, Sandoval 2016, Bergh and Sloboda 2010). Para este tipo de exploración intelectual es fundamental tener presente que la música también ha sido utilizada muchas veces para suscitar violencia, guerras y agresión (Cusick 2006 y 2008, Kartomi 2010, Kent 2008, Bergh and Sloboda 2010, O'Connell 2010). Por eso, una lección fundamental para el estudio de la música en el contexto de la construcción de paz es que ésta no es una práctica inherentemente positiva o socialmente constructiva. Lo que la música hace en la sociedad depende tanto de su contexto histórico y sociocultural como de las diversas percepciones locales y externas sobre ella. Por eso, alejándome de una postura que busque argumentar que la música es inherentemente buena para la construcción de paz, prefiero enfatizar la importancia del contexto histórico y sociocultural específico de la comunidad a la hora de planear, evaluar o investigar proyectos sobre música y transformación de conflictos (Sandoval 2016, Bergh and Sloboda 2010).

El contexto de Libertad es particular, pues allí la gente posiciona la música como práctica de construcción de paz, no por su carácter terapéutico (en contextos clínicos, por ejemplo), sino porque se alinea con una historia ancestral de prácticas colectivas similares y también con las dinámicas actuales de rehabilitación comunitaria, en las que marcadores de identidad, tales como eventos de la historia local o ciertas expresiones culturales, son fundamentales. Los proyectos musicales que orienten sus prácticas hacia procesos de integración social deben responder a las demandas específicas de su realidad sociocultural. Un claro entendimiento de la historia local, combinado con la consideración de escenarios sociopolíticos actuales y la existencia de prácticas artísticas colectivas que dialoguen con las necesidades locales, son aspectos que pueden contribuir a la creación de contextos sociales que faciliten prácticas musicales locales emancipatorias, como en el caso de Libertad.

La música juega diversos papeles en diversos contextos sociales. Al menos otro proceso de reparación colectiva en la región Caribe (Las Pavas) había incluido la música como aspecto importante del proceso de reparación. Sin embargo, el caso de Libertad revela cómo el rol social y los efectos potenciales de las prácticas musicales pueden apoyar procesos de rehabilitación social en regiones en conflicto y post-conflicto en Colombia. Este artículo analiza la política cultural en el post-conflicto y las políticas de la identidad tal y como se manifiestan desde lo social y lo político inherente a las prácticas musicales y otras expresiones populares en Libertad, contribuyendo así a los debates sobre el rol de las prácticas culturales en las políticas públicas de desarrollo.

\section{Música en la Libertad del post-conflicto}

Libertad es un pequeño pueblo afrocolombiano en la costa Caribe, ubicado en una de las regiones más antiguas de asentamiento de personas afro libres en el país, evidenciando actividad desde inicios del siglo XVII (Arrázola 1970). El conflicto armado llegó a esta comunidad a mediados de la década de 1990 cuando el Frente Golfo de Morrosquillo, un comando paramilitar perteneciente al Bloque Héroes de Montes de María de las Autodefensas Unidas de Colombia, ocupó el pueblo por cerca de una década, cometiendo toda clase de agravios, crímenes violentos y acciones de control social sobre la población civil. Durante la ocupación, los paramilitares llevaron a cabo desapariciones forzosas, asesinatos, torturas, trabajos forzosos, abundantes abusos sexuales, la disrupción de órdenes rituales tradicionales y la prohibición de ciertas tradiciones culturales locales, lo que llevó a un quebrantamiento de las relaciones sociales y al fin de los encuentros comunitarios en el pueblo (OIM 2012a, 93).

Entre 1997 y 2004, Marco Tulio Pérez Guzmán, alias "El Oso", comandante del Frente Golfo de Morrosquillo, decidió controlar o prohibir todas las iniciativas comunitarias, incluyendo expresiones culturales musicales y dancísticas como el bullerengue y los tradicionales velorios funerarios afrocolombianos. Estas prácticas culturales han sido fundamentales en esta comunidad, precisamente, porque generan contextos para la integración social, la solidaridad y surgimiento de la empatía entre vecinos. Este era el caso, por ejemplo, durante las fiestas patronales, amenizadas con músicas locales, o durante las nueve noches de los velorios fúnebres, donde se daba espacio a la comunidad entera para reunirse y revalidar lazos. Las acciones de los paramilitares tuvieron un fuerte impacto en el tejido social de la comunidad, pues desarticularon las redes de músicos y especialistas rituales, desplazaron la autoridad de los mayores y otros líderes locales, generaron aislamiento entre los miembros de la comunidad y sembraron la desconfianza entre ellos.

Ese frente paramilitar perdió el control de Libertad y fue expulsado por la comunidad en 2004, antes de que se sancionara, pero cuando ya se estaba gestando, el trámite de la Ley de Justicia y Paz (Ley 975 de 2005). Esta ley, apoyada con firmeza por el gobierno del entonces presidente Álvaro Uribe Vélez, buscaba la desmovilización de estos grupos armados ilegales en todo el país, si bien a costa de una enorme impunidad para la mayoría de sus combatientes y comandantes, incluyendo indultos por innumerables crímenes de lesa humanidad. Dichas impunidades fueron fuertemente criticadas por políticos de la oposición y organismos defensores de 
los derechos humanos a nivel mundial, lo que está documentado en la prensa del momento (Forero 2005, Muñoz 2010). Sin embargo, esta ley también incluyó las primeras directrices a nivel nacional para la reparación colectiva de víctimas del conflicto, a través de los PIRC. El diseño de los primeros siete pilotos de PIRC, incluido Libertad, inicia en el año 2007 y en 2012 comienza la implementación de dicho plan en esta comunidad.

Actualmente, el PIRC de Libertad es administrado por la Unidad para la Atención y Reparación Integral a las Víctimas (UARIV). Esta agencia del gobierno se creó en 2014 cuando la Ley de Víctimas (Ley 1448 de 2011) reemplazó los aspectos sobre reparación colectiva de la ley de Justicia y Paz y reconoció a las víctimas del conflicto como sujetos diversos histórica y socioculturalmente, incluyendo así el llamado "enfoque diferencial" en la política pública sobre víctimas. $\mathrm{Al}$ igual que los otros PIRC, el plan de reparación de Libertad busca reparar daños específicos causados por el conflicto para así facilitar desarrollos en otras áreas, tales como servicios de salud e infraestructura. Su metodología se basa en principios del desarrollo participativo que enfatizan la importancia de la participación comunitaria en el diseño e implementación de proyectos, incluyendo aquellos orientados a la integración comunitaria y la reconstrucción de relaciones sociales en la comunidad (OIM 2012a).

El PIRC de Libertad es interesante porque en él se propone explícitamente usar las músicas tradicionales y otras expresiones culturales como mecanismos para la construcción de paz. Esto aparece en el PIRC como parte del Programa III para la Recuperación de la Convivencia y el Desarrollo Social, con dos objetivos específicos: 1) lograr la reintegración intergeneracional usando expresiones populares tradicionales, tales como el bullerengue y los juegos cantados de velorio; y 2) proveer espacios, incluyendo un centro cultural y una emisora comunitaria, para promover el diálogo público y abierto, el acceso a la información y la promoción de la cultura local (OIM 2012b). Sin embargo, a pesar existir planes integrales como el PIRC, en Libertad las iniciativas de construcción de paz pueden variar desde programas locales sin apoyo externo, hasta campañas de sensibilización a nivel nacional por parte del Estado; es un contexto social donde los estilos de vida tradicionales y rurales afrocolombianos interactúan con la cultura popular urbana del Gran Caribe; y donde el narcotráfico sigue siendo parte viva de la realidad social, influyendo en la política y a veces afectando los procesos mismos de reparación colectiva.

Estas particularidades del caso de Libertad me llevaron a preguntarme: ¿de qué manera las prácticas musicales afrocolombianas, las cuales tienen una larga historia en la región, pero que han sido reconfiguradas en el post-conflicto, ayudan a alcanzar objetivos del PIRC, así como de otras iniciativas de construcción de paz? ¿Hasta qué punto se relacionan los aspectos sobre música del PIRC de Libertad con otros esfuerzos de construcción de paz que son parte de una agenda gubernamental más amplia para la reparación colectiva, la cual incluye ciertas ideas establecidas sobre la música, la cultura y las artes?

\section{El pueblo afrocolombiano de Libertad}

Libertad es un pequeño pueblo costero en la región Caribe colombiana, corregimiento del municipio de San Onofre, departamento de Sucre. Ubicado dos horas y media al sur de la ciudad de Cartagena por tierra, esta población está anclada en la parte baja de los montes de María, serranía que ayuda a delimitar una subregión cultural de la gran región Caribe. Las comunidades montemarianas comparten cultura, actividades productivas e historia, incluyendo la memoria colectiva de resistencia contra el conflicto armado durante la segunda mitad del siglo XX. Este pueblo afro tiene una historia cultural profunda que varios mayores de la comunidad dicen data de comienzos del siglo XVII, cuando grupos de cimarronescolonos negros libres que se habían escapado de Cartagena durante las revueltas de esclavos-fundaron sus propios pueblos libres en la zona. Estos asentamientos proliferaron y luego fueron llamados palenques, entre los cuales sobresale aun hoy en día San Basilio de Palenque, el cual lleva el honroso título de "primer pueblo libre de América" - también título del libro clásico del historiador Roberto Arrázola - por haber obtenido su independencia de España por una cédula real de 1713 (cf. Arrázola 1970). La historia de este temprano asentamiento afrocolombiano en la región arroja luces sobre cómo las prácticas culturales afrocolombianas se han desarrollado y adaptado por siglos.

Libertad es un corregimiento grande, con alrededor de dos mil habitantes, la mayoría de los cuales vive en el pueblo como tal, mientras que otros están diseminados por los campos vecinos. Otros tres asentamientos menores-Sabanetica, Pisisí y Arroyo Seco-los cuales suman en total alrededor de mil habitantes, también están incluidos dentro del corregimiento. Libertad fue fundado en 1933 por un grupo de campesinos afrocolombianos sin tierra, quienes invadieron terrenos baldíos que habían sido previamente reclamados por familias terratenientes (García Caraballo 2012). Desde su fundación, Libertad ha sido un pueblo agricultor, produciendo y exportando arroz, coco, maíz, yuca, ñame, ajonjolí, plátano, caña de azúcar, limón y productos lácteos, entre otros. Anteriormente, los campesinos navegaban en veleros hasta Cartagena para vender sus productos en el mercado de Bazurto. Hoy en día, transportan sus productos en bus o camión a los mercados regionales en San Onofre, Sincelejo y Cartagena.

Tierra campesina por tradición, Libertad ha estado aislada históricamente del resto de la nación y, hasta cierto punto, 
del gobierno nacional. El calendario local y las actividades anuales son dictados por los ciclos agrícolas. A pesar de su tamaño, el pueblo tiene sólo una enfermera y un médico, el último sólo disponible en el pueblo cuatro días a la semana. Una sola farmacia brinda acceso a medicamentos básicos. El pueblo no tiene alcantarillado y la mayoría de los hogares no tiene agua corriente. El servicio eléctrico fluctúa y con frecuencia daña los electrodomésticos. El acceso a señal de telefonía celular también es fluctuante y suele ser poco fiable para realizar actividades pesadas de Internet. A pesar de tener una iglesia pequeña, no hay cura residente, aunque uno es llamado de la Arquidiócesis de Sincelejo cuando es necesario. Los servicios de computador e Internet son escasos y pocas casas tienen computadores e impresoras, mientras que un sólo quiosco de Internet ofrece servicio al público.

Los liberteños celebran las festividades locales con comida, juegos, alcohol, música y baile. Entre las celebraciones locales más importantes están la Semana Santa, la fiesta patronal de la Virgen de las Mercedes (29 de septiembre), el Día de los Difuntos (2 de noviembre), la Independencia de Cartagena (11 de noviembre) y Navidad. Anteriormente, estas celebraciones las acompañaba hasta el amanecer el grupo local de "baile cantao," que es otro término local para referirse al grupo de bullerengue, manifestación musical y dancística afrocolombiana protagonizada por los "repiques" de los tambores tradicionales (un tambor mayor y un tambor llamador), las tonadas y coros de cantadoras y cantadores, y los "pases" de los bailarines. Para estas fiestas a veces también se contrataban grupos locales o regionales de música de gaitas y tambores, o "fandangos", que es otro nombre para referirse a las bandas regionales de vientos, quienes interpretan porros y fandangos. Esta práctica se ha debilitado en las últimas décadas y grandes sistemas de sonido o picó, contratados para tocar selecciones de músicas populares caribeñas, como vallenato, champeta y reguetón, entre otros, han reemplazado a estos grupos en las calles del pueblo. Sin embargo, recientemente se usaron bandas de vientos para ciertas actividades y las prácticas locales de bullerengue han comenzado a reactivarse.

Entre las preparaciones gastronómicas especiales para las celebraciones locales, se encuentran: el pescado guisado en salsa criolla con arroz de coco y fríjol negro con patacones, acompañado de ensalada de remolacha; la sopa de costilla de res con yuca, plátano y ñame; y el arroz de coco y cerdo con buñuelos de maíz verde con queso y ensalada verde. Es común compartir comida durante tiempos festivos y las invitaciones a comer a las diferentes casas abundan. Los liberteños son gente hospitalaria y festiva, siempre buscando oportunidades para conversar y contar un chiste o una historia entretenida. Además, echan mano de gran repertorio de juegos de mesa y juegos cantados/actuados los cuales juegan durante dichas celebraciones o en otras ocasiones especiales. La mayoría de juegos cantados en esta zona, sin embargo, pertenecen al contexto ritual de los velorios funerarios, al ser un elemento primordial del entretenimiento en estas importantes reuniones comunitarias, con el fin de mantener a los participantes despiertos entre los distintos ciclos de rezo y oración durante las nueve noches.

En alianza con grandes políticos y terratenientes de la región, los paramilitares tomaron el control de toda la región de los montes de María durante la década de 1990, expulsando a la guerrilla y protegiendo los intereses de algunas élites regionales, así como el control de las rutas del narcotráfico. En este contexto llegaron al pueblo Marco Tulio Pérez, alias "El Oso," y sus paramilitares en 1997. El Oso era el comandante del Frente Golfo de Morrosquillo, escuadrón del Bloque Héroes de Montes de María de las Autodefensas Unidas de Colombia, el mayor ejército terrorista antisubversivo y de extrema derecha del país en ese momento. El Oso y su gente estuvieron en Libertad ocho años, explotando y abusando de la población local mientras protegían los intereses económicos de su proyecto narco-paramilitar.

Hoy en día, los residentes recuerdan este periodo como "la violencia" y lo consideran el más duro que la gente de Libertad haya vivido." ${ }^{2}$ El Oso y sus alrededor de cien hombres y colaboradores impusieron un reino del terror, robando tierras, bienes y dinero a la gente, cometiendo tres masacres, violando decenas de mujeres, actuando como ley de facto, exigiendo todo tipo reverencias y castigando a cualquiera que se les opusiera. Durante este periodo, la mayoría de actividades comunitarias fueron controladas o prohibidas. Sin la existencia de los eventos sociales y culturales que ocurrían con regularidad y que anteriormente integraban a los miembros de esta comunidad en un solo cuerpo social, la gente se aisló y la desconfianza entre vecinos creció. Después de que los paramilitares fueron finalmente expulsados de la comunidad en el año 2004, el Plan Integral de Reparación Colectiva de esta comunidad empezó a tomar forma a través del esfuerzo colectivo de los líderes locales y el gobierno central.

Dos casos permiten evidenciar cómo las prácticas musicales pueden generar oportunidades de fortalecimiento comunitario y para la construcción de paz en contextos de post-conflicto en el pueblo de Libertad: 1) la revitalización de cantos y juegos tradicionales pertenecientes al contexto ritual de los velorios funerarios, una actividad que cumple funciones de estimular la solidaridad y cooperación entre vecinos, revalidar lazos y acompañar a la familia doliente; y 2) el desarrollo de un nuevo género musical local bautizado bullenrap, creado por el colectivo musical Afro-Música en los Montes de María (Afro-Música, de ahora en adelante), quienes a través de una fusión de bullerengue tradicional y hip-hop buscan revitalizar las prácticas musicales locales y fortalecer las relaciones intergeneracionales, una de las necesidades específicas identificadas en el PIRC. Otros casos documentados en el mundo también muestran cómo los líderes locales son actores clave en la potenciación de prácticas musicales colectivas orientadas a la construcción de paz, administrando 
los recursos culturales de manera estratégica, empoderando a los miembros de la comunidad y creando espacios para trabajar, acompañar, socializar y hacer música juntos, como por ejemplo, en el caso de conciertos de ensambles de músicos croatas y rom en Austria y Croacia, orientados a sensibilizar al público sobre interculturalidad, tolerancia y la situación migratoria (Pettan 2008, 92-96).

\section{Los juegos cantados de velorio}

Los velorios fúnebres tradicionales afrocolombianos han sido una práctica popular y frecuente tanto en las costas Pacífica como Caribe colombianas. Estas prácticas involucran un orden ritual que incluye una mezcla de actividades religiosas y seculares que inician la noche siguiente al entierro del finado en su casa, donde se ha instalado el altar. Durante un periodo de nueve noches se deben realizar ciclos específicos de tres o más rosarios y oraciones frente al altar. Estos rezos suelen estar distribuidos a lo largo de toda la noche, durante cada una de estas nueve noches, momento en que cientos de personas de la comunidad visitan la casa. Entre ciclo y ciclo de oración, la gente cuenta historias, chistes, juega dominó, naipes y también juegos cantados. Existe un repertorio completo de juegos cantados de velorio cuya función es crear y mantener un ambiente enérgico y alegre, de esta manera distrayendo a los dolientes y entreteniendo a los asistentes entre ciclo y ciclo de oración, para que no se duerman. En este contexto, la solidaridad con la familia doliente es prioridad y son múltiples las personas que ayudan a la familia en la organización de todo el evento. Un buen velorio es caro, y la cantidad de asistentes depende de la popularidad e importancia en vida de la persona en la comunidad. En estas reuniones se reparten durante la noche café negro y "calentillo," el cual es una bebida caliente a base de jengibre y hierba-limón.

El juego es parte crucial de los velorios en Libertad, y cuando la gente, incluyendo a los niños, no está contando chistes o cuentos, está jugando dominó, naipes o juegos de velorio. En este sentido, esta tradición manifiesta un balance entre lo sagrado y lo secular, tal cual lo describimos con John McDowell en la introducción para el libro póstumo de George List, Animal Tales from the Caribbean:

Los rezos se hacen al menos dos veces durante la noche, aunque con mayor frecuencia, tres: a las nueve, a medianoche y cerca al amanecer, hacia las cuatro de la mañana. Cada ciclo de oración es coordinado por las rezanderas, quienes son especialistas en estos asuntos. Ellas son profesionales entrenadas quienes reciben remuneración por su participación en el velorio. Su trabajo ritual es parte fundamental de la ceremonia y constituye el aspecto sacro de la misma. Los rezos canalizan los esfuerzos humanos por solicitarle a Dios misericordia con el alma que se va. Las sesiones de oración están estructuradas a través de rosarios, lo que determina cuando ciertas oraciones y rezos son hablados o cantados en voz alta. Estos rezos pueden cambiar, dependiendo de la hora, el significado religioso específico del día, $\mathrm{u}$ otras razones que dependen del trabajo de cada rezandera. La mayoría de las oraciones son en forma de pregunta/respuesta y los asistentes a los velorios, por lo general, suelen saber las "respuestas" a las partes solistas de la rezandera. Las oraciones más comunes en estas ocasiones son: Padre Nuestro, Ave María, Credo, letanías y una larga oración final que es la contribución específica de cada rezandera.

Cuando los rezos terminan el entretenimiento continúa. Sin embargo, el tipo de entretenimiento apropiado depende de si el finado es un niño (angelito) o un adulto. En el sistema local de creencias, los niños hasta alrededor de los diez años son considerados "angelitos", lo que quiere decir que son inocentes, no han pecado, y van directamente al cielo. Por tal razón, rezar es innecesario en un velorio de angelito y estos eventos solo duran una noche, la Primera Noche, que es cuando hay "cuerpo presente" (...) Aunque el velorio de un niño es un momento de luto, la atmósfera es más festiva pues esta muerte es vista como el nacimiento de un nuevo ángel en el cielo. La gente cree que estos "angelitos" protegerán a los miembros de su familia y amigos" (Rojas y McDowell 2017, 142-143).

En este sentido, existe concordancia entre la información recogida por George List en el Caribe colombiano en la década de 1960, y las prácticas documentadas por mí en Libertad cincuenta años después, entre 2014 y 2018. En el contexto del velorio se manifiesta una separación entre el espacio del entretenimiento - afuera, frente a la casa, donde se juega, se canta y se cuentan cuentos-y el espacio de lo sagradoadentro, en la sala de la casa, donde está el altar y donde se hacen los tres rezos cada noche.

Afuera de la casa se ubican sillas, tantas como pueda conseguir la familia. La gente empieza a visitar la casa cuando comienza a oscurecer. Hay personas que se demoran poco $\mathrm{y}$ otras que se quedan toda la noche; algunos van una sola vez, mientras que otros van varias veces durante la novena. En los velorios se encuentra gente de todos los contextos sociales en Libertad, si bien las clases más acomodadas de Libertad, los dueños de tierras y quienes viven alrededor del parque principal del pueblo, suelen celebrar sus velorios sin juegos, y mucho más de acuerdo con el canon católico.

Durante los largos períodos de tiempo entre rezo y rezo, uno de los entretenimientos más comunes es el dominó. 
Este es un juego que practican tanto niños como adultos y en una noche de velorio puede fácilmente haber cuatro o cinco mesas de dominó. Tradicionalmente también se solía jugar un juego con el naipe español llamado "truco." Es un juego complejo y, en la actualidad, solo algunos mayores aun lo practican y conocen a cabalidad sus reglas. George List (2017) documentó todo un repertorio de cuentos y chistes de velorio, especialmente un corpus de cuentos de animales, algunos de los cuales son aun contados actualmente en Libertad. Sin embargo, según pude documentar durante al menos dos velorios, actualmente los "cuentos" hacen referencia a, efectivamente, el performance de la "cuentería" y la narración oral, pero el material narrado no hace parte de este corpus tradicional, sino que se cuentan historias de la cotidianidad, reales o inventadas, pero exageradas y caricaturizadas, usando personajes presentes o conocidos para hacerlas más graciosas. Igualmente, "contar cuentos" en Libertad también puede hacer referencia a contar chistes, una polisemia que también había documentado ya George List (Rojas y McDowell 2017, 144-145).

Además de los juegos de mesa y otras expresiones recién mencionadas, es característico de los velorios en Libertad el performance de un repertorio de juegos cantados y actuados que se juega específicamente en este contexto ritual, si bien desde 2014 también hace parte de representaciones escénicas de la cultura liberteña, tipo "muestra folklórica", con la idea de mostrar las tradiciones locales afuera y a los visitantes. Estos juegos tienen todos en común que son grupales, siempre hay un líder y siempre existe una canción, la cual tiene una estructura de pregunta-respuesta, en la cual la pregunta la hace el líder y la respuesta, el resto de los jugadores. Además, estos juegos suelen involucrar algún tipo de actuación o movimiento físico, que puede ser desde marchar rítmicamente en círculo o culebreando en fila india, mientras se atienden las reglas del juego y se cantan las respectivas canciones. Varios de estos juegos cantados de velorio se practicaban de forma similar en otras zonas rurales de la costa Caribe, según documentado por List, mientras que otros tienen paralelos con juegos cantados de velorio documentados en la costa Pacífica colombiana (List 2017; De Granda 1977).

Algunos de los juegos más practicados en Libertad son "El café," "La chancleta," o "A pilá' el arró," pero el más popular y el que más se juega se llama "La marucha." De hecho, este juego es tan central en este repertorio que es común que a todo este género de juegos cantados de velorio se le denomine localmente y de manera general como "maruchas". El juego consiste en hacer una ronda circular tomándose de las manos entre varias personas, brincando todos al unísono en la misma dirección, siguiendo el ritmo de la canción y cantando las siguientes líneas en forma de pregunta/respuesta, esperando para responder después de que quien dirige la canción cante la parte solista, mientras brinca sola y en la misma dirección adentro del círculo: ${ }^{3}$

\author{
La patilla serenada \\ Prima hermana del melón \\ La patilla serenada \\ Prima hermana del melón \\ Quítame esta pesadilla \\ Que llevo en el corazón \\ ¡Ay Marucha! \\ ¡Trucha que trucha que trá! \\ ¡Ay Marucha! \\ ¡Trucha que trucha que trá! \\ ¡Ay Marucha!
}

Después de esta introducción y el inicio de la respuesta por parte del coro (“iTrucha que trucha que trá!"), el tempo de la canción se incrementa y quien dirige el juego comienza a improvisar una letra con contenido sexual explícito, el cual funge como bálsamo hilarante que invariablemente genera risa incontrolable y gran algarabía entre los presentes. En esta segunda parte de la canción, la respuesta del coro cambia (“'Ay Marucha!”; ver Apéndice):

Dale el colmillo a la chucha

¡Ay Marucha!

Como que quiere morder

¡Ay Marucha!

Trucha, que trucha, que trá

¡Ay Marucha! (sigue respondiendo)

Ténganle bien la cortada

Trucha, que trucha, que trá

Búscate un buen zapatero

Pa que te raspe los pelos

Trucha, que trucha, que trá

Búscate un buen zapatero

$\mathrm{Pa}$ que te raspe los pelos

Denle moquito chorreado

Pa que se termine de casar

Trucha, que trucha, que trá

Busca una buena mondá

Pa que la tengas clavá

Búscate un huevo mondao

Pa que lo tengas clavao

Trucha, que trucha, que trá

Busca una buena mondá

Pa que la tengas clavá

Trucha, que trucha, que trá

Denle la rula a la chucha

Como que quiere cortar

Ya me cortó mi mondá

De eso no hay mucho que hacer

Trucha, que trucha, que trá

Denle el lapicero a la chucha

Como que quiere escribir

Trucha, que trucha, que trá 
Mira la calle está clavá

Denle los zapatos a la chucha

Como que quiere bailar

Trucha, que trucha, que trá

Busca una buena mondá

Busca tu huevo mondao

$\mathrm{Pa}$ que lo tengas clavao

Busca tu huevo mondao

Pa que lo tengas clavao

(...)

El contexto que rodea el juego de "La marucha" en los velorios liberteños - al menos en seis de ellos que he tenido la posibilidad de documentar - siempre es de risa, algarabía, humor y conexión grupal a través de la alegría. El juego de "La marucha" no pasa desapercibido y se convierte en el foco de la atención de todos los presentes; hasta las personas más acongojadas sueltan una sonrisa, pues todo el entorno fúnebre se transforma, la energía social sube, se incrementa la frecuencia de las interacciones, así como el volumen de las mismas, y también su contenido jocoso y de risas. La letra de este juego cantado utiliza gran cantidad de vocablos regionales y narra una serie de comportamientos de agresión física entre los genitales femeninos (la chucha) y los masculinos (la mondá). Lo explícito del contenido de la letra, sumado a la maestría del performance del líder del juego, en este caso la maestra Isabel Martínez "Chabelo", quien canta en tono alto y a gran volumen, vociferando versos graciosos con gran cantidad de palabras relacionadas con la actividad sexualclavar, dar por delante, dar por detrás, huevo mondao, etc.son una fórmula segura para la risa y el goce colectivo. De alguna manera, es como si la terrible e innegable presencia de la muerte, que visita la comunidad y se lleva a uno de sus hijos, fuera enfrentada a través de prácticas que involucran ciertos niveles de transgresión controlada del discurso con el fin de generar cierta presión social, la cual suele ser desfogada a través de la risa, el relajamiento y la conexión con las personas presentes.

Debido a su naturaleza colectiva y a su impacto fortaleciendo la cohesión social a nivel local, los velorios fueron prohibidos por los paramilitares, quienes impidieron a las personas la posibilidad de lidiar con sus muertos de la manera ritual y tradicional. Esta opresión tuvo consecuencias que, sumadas al resto de prácticas violentas de los ocupadores, empezaron a generar alienación y a afectar el tejido social. Nada reemplazó estos mecanismos que cumplían la función de revalidar lazos ceremonialmente, facilitando contextos para la integración social. La desconfianza empezó a reinar, pues todos temían que algún vecino anónimo, por asuntos personales, los fuera a injuriar y calumniar ante los jefes paramilitares, buscando beneficios particulares. A pesar de las enormes dificultades, líderes locales como Chabelo se han destacado como guardianes de estos y otros conocimientos tradicionales de esta comunidad. Estas tareas de liderazgo requieren procesos de organización comunitaria, actividades que Chabelo ha manejado de manera independiente, si bien se han fortalecido con el plan de reparación colectiva.

Siendo Chabelo una maestra reconocida localmente por su experiencia de toda la vida liderando y practicando los juegos de velorio, aproximadamente desde 2012 ha dirigido de manera intermitente un semillero con sus nietos y otros niños de la comunidad para transmitir, revitalizar y perpetuar esta práctica, importante para la validación de lazos sociales a nivel local. Con tenacidad, Chabelo resistió valientemente las prohibiciones de los paramilitares y siguió facilitando velorios tradicionales, con la autorización de los dolientes. Así, logró que la memoria colectiva asociada a estas prácticas se mantuviera activa, y no dormida o en letargo, solamente asociada a prácticas antiguas o de "los tiempos de antes" de la ocupación. Con el mismo liderazgo, su participación fue fundamental cuando los procesos de reparación colectiva llegaron a Libertad, y fue la primera en liderar procesos locales asociados a las expresiones culturales locales. En este contexto, también fue la primera en facilitar, junto con otras mujeres de la comunidad, puestas en escena de tipo folklórico representando los juegos de velorio como práctica representativa de la comunidad de Libertad.

En la actualidad, la gente ha recobrado la expectativa de los velorios como una práctica frecuente y como un espacio para la intensificación de la interacción social y el desarrollo comunitario. Los velorios tradicionales son considerados nuevamente como espacios de apoyo y reconciliación, un sentido que se había perdido durante los tiempos de los paramilitares. Chabelo es una líder fuerte que se ha encargado de buena parte del trabajo relacionado con esta iniciativa de revitalización cultural, algo que la comunidad reconoce. Sin embargo, para esto sus proyectos también ha tenido apoyo del PIRC y de algunas ONG, ayudándola a legitimar su trabajo comunitario y brindándole capacitación, por ejemplo, en técnicas de rehabilitación psicosocial. Durante mi trabajo de campo en Libertad pude documentar siete velorios fúnebres y sus novenas, uno solo de los cuales fue un velorio de niño. De estos siete velorios, en seis de ellos se jugaron los juegos de velorio, lo que marca una importante diferencia con los tiempos de la prohibición y el periodo de crisis social y económica que siguió a la ocupación paramilitar.

\section{El bullenrap del colectivo Afro-Música}

En cuanto al bullenrap es importante resaltar que los ancestros de músicas y bailes que hoy en día conocemos como gaita y bullerengue, han sido centrales en esta región al menos desde el siglo XVII, según textos de algunos cronistas que documentaron descripciones de estas prácticas y 
también los intentos de la Iglesia Católica y la Corona por prohibirlas o controlarlas (Navarrete 2012). Y aunque estas tradiciones están muy fortalecidas en otras zonas de la costa Caribe colombiana, estaban desapareciendo en Libertad, pues la gran mayoría de sus practicantes murieron y solo unos pocos mayores de avanzada edad siguen con vida. Durante la ocupación paramilitar se gestó una brecha generacional fuerte entre los jóvenes del pueblo y los adultos mayores de 40 años, aproximadamente, lo que hizo que ningún músico joven se interesara por aprender los saberes de los mayores. Esta brecha surgió durante la ocupación como respuesta a una alteración profunda en el orden social y la transmisión de valores ancestrales en la comunidad: los adultos y ancianos, quienes históricamente habían ejercido el rol de líderes, sabedores y autoridad en la comunidad, fueron desplazados por un grupo de jóvenes armados, los paramilitares, quienes se convirtieron en autoridad y modelo a seguir para los niños que crecieron en el pueblo durante este periodo. Con el paso del tiempo, esto generó una profunda división intergeneracional, en la que los mayores consideraban que los jóvenes, en general, eran irrespetuosos y abusivos, y los jóvenes pensaban que los mayores, en general, los menospreciaban y no los tomaban en serio. En realidad, solo hasta la actualidad se está resolviendo esa brecha, en parte gracias a la iniciativa de un grupo proactivo de jóvenes músicos, quienes iniciaron en la música como raperos, pero que ahora también se dedican a practicar y enseñar músicas tradicionales afrocolombianas del Caribe.

Durante y después de la ocupación, nadie tocaba música en Libertad. El pueblo vivía triste, en silencio, traumatizado y con miedo, a pesar de ya no estar sometidos por invasores. Esto empezó a cambiar, parcialmente, hacia 2012, cuando un grupo de jóvenes cantantes y compositores comenzó a hacer canciones de hip-hop con agudos comentarios sociales en lenguaje directo y, a veces, incluso agresivo. Este grupo se llamó Los Dioses y era liderado por Luis Miguel Caraballo, también conocido como "Ralam," un joven que entonces era director de la emisora comunitaria de Libertad. Estos jóvenes crecieron influidos por el vallenato, la champeta y otros ritmos de la música popular afro-caribeña como el reguetón y el rap puertorriqueño. En aquel momento, Los Dioses desarrollaron una estética cercana al gangsta rap, representando actitudes y líricas duras, agresivas y críticas, enfocadas en su propia realidad de gueto: las fuertes condiciones de marginación social, política, económica y cultural de los liberteños, particularmente los jóvenes, en el contexto local de postconflicto.

El rap o hip-hop, es un estilo musical que nació en la década de 1970 en el distrito del Bronx, en Nueva York, el cual se expandió rápidamente, primero como símbolo de los movimientos contraculturales afroamericanos, y luego como uno de los estilos más ubicuos en la industria musical global, según Grove Music Online. Los exponentes de este género musical revolucionaron la historia de la música popular con sus múltiples innovaciones en la interpretación vocal, el contenido lírico de sus canciones, por el uso de beats y fragmentos musicales pregrabados y secuenciados en vivo-algo sin precedentes hasta el momento y que consolidó la figura del disc-jockey o DJ-y por su explícita reivindicación de valores estéticos y culturales afroamericanos, insertando fuertes discursos de crítica social en el mercado global de la música.

La expansión global del rap fue un fenómeno que se dio en la década de 1980 gracias a su éxito comercial, su inserción en la cultura popular global a través del cine y la construcción de identidades creadas por un sentido común de "marginalidades colectivas" (Motley y Henderson 2007). Si bien esta música había recibido ya influencias de la cultura musical caribeña, por ejemplo en el uso del sound system, inspirado en el dancehall jamaiquino (George 2004), el hip-hop tuvo fuerte impacto en algunas zonas del Caribe como Jamaica, Panamá y Puerto Rico, donde géneros como el raggamuffin, reggae panameño y rap latino, por solo mencionar algunos, han tenido influencias de este género musical afronorteamericano. De esta forma, la expansión de formas musicales relacionadas con el hip-hop tiene una historia larga en el Caribe. Desde la década de 1980, de hecho, ya habían comenzado a llegar discos de rap a los puertos de Buenaventura, Cartagena y Barranquilla (Dennis 2012:21-23). Estas músicas adquieren mayor difusión en el Caribe, y también en toda Colombia, iniciando la década de 1990, después del éxito descomunal del reggae panameño, que en Colombia fue llamado "meneíto," y cuyo exponente más importante a nivel nacional fue El General.

Si bien el grupo liberteño Los Dioses se disolvió por la presión económica que hizo que sus miembros migraran a buscar trabajo en Cartagena, Ralam volvió pronto a Libertad con la idea de continuar su proyecto musical, esta vez con niños, jóvenes y adultos mayores de la comunidad. En 2015 formó un nuevo colectivo, el cual tomó el nombre de AfroMúsica en los Montes de María, con alrededor de 20 jóvenes de la comunidad. Este colectivo se enfocaba también en la práctica y composición de canciones de rap, con mensajes alusivos a las realidades locales, las cuales eran cantadas sobre pistas de hip-hop bajadas de internet. Durante ese año, varios líderes de este colectivo comenzaron a participar en procesos de capacitación en liderazgo comunitario en el marco del PIRC, incubando el interés por desarrollar una forma artística que se alineara de manera directa con los procesos de rehabilitación comunitaria, centrales en la ruta de reparación colectiva. De esta forma, Afro-Música comenzó a diferenciarse de Los Dioses al utilizar líricas con mensajes más positivos socialmente, menos enfocados en una crítica social con carácter de confrontación. Aquí, un fragmento de la canción "Si quieres ver a Libertad" (2015), compuesta por Afro-Música: ${ }^{4}$ 
Coro:

Si quieres ver a Libertad

Un pueblo en que se puede soñar

Pues yo te la voy a mostrar

Ven conmigo y vive la realidad

Cada mañana que me despierto y veo

A mi familia tan feliz, ni yo mismo la creo

Mamá me dice que sonría y que debo ser feliz

Sepan todos que es un orgullo para mi ser de aquí

Aunque pasó la violencia y nuestra vida cambió

El dolor y la tristeza en nuestras vidas pasó

No somos pueblo de guerra, somos un pueblo de paz

Somos la juventud que sueña que puede progresar

Otra consecuencia de la participación de los líderes de Afro-Música en los procesos de la Unidad de Víctimas fue el impulso para investigar las músicas locales y de tradición, aquellas que habían tocado los mayores por generaciones antes que ellos, pero que ellos no conocieron al crecer, pues casi no se practicaban. Así, Ralam y Afro-Música empezaron a desarrollar una nueva expresión musical, el bullenrap, que mezcla bullerengue y rap. Si bien el PIRC de Libertad no contemplaba necesariamente la participación de liderazgos jóvenes dentro de los comités que administran este plan de reparación, los jóvenes de Afro-Música se dedicaron a trabajar directamente con los adultos mayores, asistiendo a sus reuniones, realizando entrevistas y una especie de grupos focales con ellos, con el fin de recoger información sobre las tradiciones ancestrales y las prácticas culturales de antaño. Con base en la información recogida, los jóvenes artistas se aliaron con los bullerengueros y sabedores tradicionales locales, como Chabelo, y comenzaron a componer canciones de bullenrap, mezclando elementos del hip-hop que ya conocían (y que tan tanto les gustaba) con el bullerengue que estaban comenzando a estudiar. En este proceso, yo mismo tuve la oportunidad de colaborar con Afro-Música facilitando talleres de percusión tradicional afrocolombiana y gestionando recursos para llevar a la comunidad, junto con la Corporación Sonidos Enraizados, al maestro bullerenguero Emilsen Pacheco de San Juan de Urabá, en 2016, para desarrollar procesos de formación en percusión tradicional.

El bullerengue es una práctica musical colectiva de herencia afrocolombiana, la cual parece ser una de las expresiones tradicionales más antiguas aun vigentes en la costa Caribe colombiana. Su origen parece ser el actual departamento de Bolívar, habiendo descripciones similares a lo que hoy se conoce como bullerengue desde finales del siglo XVIII. Sin embargo, esta práctica se difundió a través de migraciones por toda la costa, así como por la zona del Canal del Dique y algunos otros pueblos ribereños. El bullerengue consiste en el canto responsorial de "tonadas" por parte de un cantante solista, al cual un coro le responde un estribillo constante, acompañados siempre por dos tambores cónicos monomembranófonos, el llamador - más pequeño y que mantiene una base constante-y el tambor alegre-más grande y que acompaña y hace variaciones de acuerdo con el desarrollo del canto y el movimiento de los bailadores. El baile consiste en una pareja que se enfrenta y da vueltas cadenciosamente, de forma sensual pero sin tocarse, moviendo suave y ágilmente las caderas de forma circular y sin levantar los pies del suelo (Rojas 2013).

Esta música, que en diversas localidades campesinas aun se le llama de otras formas, como tuna, porro, o baile cantao, tiene ahora su foco más fuerte de actividad en la zona de Urabá. Actualmente, tres festivales de bullerengue - en Necoclí (Antioquia), Puerto Escondido (Córdoba) y María la Baja (Bolívar) - son los eventos más importantes de esta tradición musical, aunque hace 50 años todavía estaba asociada a diversas fiestas religiosas, como Pascua o las fiestas patronales, a fiestas cívicas como la independencia de Cartagena, o a celebraciones privadas. Hoy en día se le suelen reconocer tres variantes rítmicas: bullerengue sentao, chalupa y fandango de lengua. Por su estructura basada en tambores, canto responsorial y danza ligera y expresiva, elementos usualmente atribuidos a ciertas músicas de África Occidental, el bullerengue suele ser asociado con una fuerte herencia africana y con procesos de construcción de identidad afrocolombiana.

El bullenrap, nuevo género musical creado por AfroMúsica que mezcla bullerengue y hip-hop, no está orientado solo a recrear y representar en la actualidad el contexto participativo del performance tradicional de bullerengue, con cantos y tambores en las calles del pueblo, sino que también está guiado por una estrategia pedagógica de enseñar tambores y composición de canciones a los niños de la comunidad. Estas actividades de formación las realiza Afro-Música desde 2015 a través de actividades diarias con los niños. Desde 2016, este proceso ha tenido apoyo del Ministerio de Cultura a través del proyecto Expedición Sensorial por los Montes de María y actualmente hay alrededor de cien niños vinculados y beneficiados en Libertad.

En cuanto al aspecto creativo, los miembros de AfroMúsica escogen estratégicamente qué elementos musicales incluir en su música, bien sea de bullerengue o rap, dependiendo de su objetivo específico. Una estrategia que han adoptado como central ha sido el uso de los tambores tradicionales, con el fin de emular un ritmo sostenido (beat), aunque éste está basado en las rítmicas del bullerengue y no del funk, sobre el cual cantan sus rimas. El uso de los tambores tradicionales también ha facilitado que el grupo se pueda desplazar mientras toca por diversas partes del pueblo, lo que ha facilitado intervenciones en el espacio público en los diversos barrios de Libertad. He aquí un fragmento del groove básico de la 
canción "A pie pelao", uno de los temas que tuvo acogida local importante en 2016 (ver Apéndice).

Sin embargo, los elementos vocales incluyen técnicas y estilos básicos del rap, con fraseos rítmicamente intensos y sincopados, aunque construidos con pocos tonos y movimiento melódico limitado. A nivel lírico, los versos acomodan las rimas rítmicamente, más que de acuerdo con la estructura silábica de la estrofa. Estos rasgos del hip-hop llaman mucho la atención de los niños, por lo que son ideales para acercar a los más jóvenes a los tambores tradicionales. Las letras tocan temas relacionados con situaciones del día a día, tales como las labores del campo, la comida local, las fiestas locales, la abundancia de mosquitos, las aventuras de Afro-Música, entre otros temas. Sin embargo, los coros (estribillos) de las canciones muchas veces son de temas de bullerengue, con la idea de que a través de esta nueva música, los más jóvenes de la comunidad sean expuestos a melodías tradicionales - como por ejemplo, "Camisola"-y que éstas empiecen a hacer parte de sus vidas. También hay composiciones de Afro-Música mucho más cercanas al bullerengue tradicional (tanto en sus versos como coros), mientras que hay otras cuyos estribillos son más cercanos al rap directamente, como el caso de "A pie pelao" (ver Apéndice).

Estas iniciativas han validado espacios para el liderazgo de los jóvenes y sus organizaciones dentro de la estructura del PIRC de Libertad. De hecho, debido al impacto social de su proyecto musical, Afro-Música está ahora oficialmente invitado a participar en el proceso de gobierno del plan local de reparación colectiva. El bullenrap y sus prácticas son una ilustración de cómo grupos motivados y organizados, de la mano de liderazgos locales fuertes y creativos, tienen la capacidad de rehabilitar el tejido social y musical de una comunidad, especialmente cuando el acompañamiento institucional se enfoca en empoderar a los líderes locales y sus iniciativas (Pettan 2008).

\section{Música, construcción de paz, reparación colectiva y reha- bilitación comunitaria}

Los conceptos de construcción de paz, reparación colectiva y rehabilitación comunitaria son tres ideas relacionadas que aparecen con frecuencia y se superponen parcialmente en las narrativas de proyectos musicales co-administrados por víctimas y el gobierno en esta comunidad. Los tres se refieren a ideas sobre el fortalecimiento de la cohesión social, la construcción de lazos comunitarios y la sostenibilidad social después de un período de disrupción, pero cada término se refiere a un proceso diferente. De esta manera, las tres ideas están relacionadas entre sí, pero cada una pertenece a su propio ámbito, tiene su propio rango y detalla un aspecto distintivo de los procesos de reconstrucción social en comunidades en post-conflicto.
Los liberteños, por ejemplo, entienden las músicas tradicionales locales como una práctica emancipatoria y transformativa, con potencial creativo, no-violento y de cohesión social. ${ }^{5}$ Estas ideas resuenan con conceptos fundacionales de las teorías de construcción de paz propuestas por estudiosos como Johan Galtung (2000: 10-24, 2008: 58). Casos de prácticas musicales colectivas liberteñas, como el bullenrap o los juegos cantados de velorio, ilustran la interrelación dinámica entre un liderazgo local fuerte, la existencia de iniciativas institucionales que enfatizan la participación local, y el aguante y resiliencia creativa de artistas locales y otros especialistas culturales. Estos procesos de transformación de conflictos están orientados a resolver tensiones sociales y a prevenir futuros conflictos. El proyecto actual de revitalización de prácticas musicales y culturales en Libertad, sin embargo, va de la mano con un proyecto educativo de base que atiende a los niños de la comunidad con clases de música y danza tradicional varias veces a la semana, proveyéndoles además oportunidades ocasionales para presentarse en vivo. Estos procesos educativos son liderados sobre todo por Ralam, bien sea como parte de Afro-Música, o como facilitador del programa Expedición Sensorial por los Montes de María, programa del Ministerio de Cultura iniciado en 2016 y que tiene por énfasis el trabajo en comunidades rurales desde la óptica del post-conflicto.

El concepto de "reparación colectiva" viene del derecho internacional y es un mecanismo judicial diseñado para atender a las víctimas cuando un conflicto ha terminado (Rosenfeld 2010). En Colombia, el término es usado por las agencias gubernamentales y la sociedad civil para referirse a programas de post-conflicto para las víctimas del conflicto armado interno, los cuales buscan mitigar el daño causado por la violencia de los actores armados involucrados en este conflicto doméstico. Tal y como se define en la Ley de Justicia y Paz (975) de 2005 y la Ley de Víctimas (1448) de 2011, la reparación colectiva incluye cinco medidas obligatorias: 1) la restitución de bienes y derechos perdidos; 2) la indemnización económica; 3) la rehabilitación comunitaria; 4) la satisfacción y dignificación de las víctimas; y 5) la garantía de no repetición de acciones victimizantes (OIM 2012a: 27-41). Las colectividades o grupos beneficiados por estas medidas son llamados Sujetos Colectivos de Reparación. Estos procesos son manejados por la Unidad para la Atención y Reparación Integral a las Víctimas (UARIV), quienes también administran el Registro Nacional de Víctimas y varios programas más relacionados con las víctimas del conflicto armado interno. Estas cinco medidas de reparación corresponden a áreas específicas que en conjunto configuran la "ruta de reparación integral", diseñada por UARIV para atender a todas las víctimas del conflicto. Mientras que algunas medidas se enfocan más en aspectos materiales o económicos (como la compensación monetaria y la restitución de tierra y bienes), otras buscan brindar seguridad, integridad o reparación simbólica. 
La rehabilitación comunitaria, como medida de reparación colectiva, consiste en "estrategias, programas y acciones de carácter jurídico, médico, psicológico y social, orientados hacia el restablecimiento de las condiciones físicas y psicológicas de las víctimas" (UARIV 2015:2). La estrategia nacional de rehabilitación comunitaria de la UARIV se llama Entrelazando, haciendo referencia a los grupos de trabajo operados a través de líderes locales, llamados "tejedores,"quienes lideran actividades comunitarias y se reúnen periódicamente entre sí y con los "entrelazadores," quienes son funcionarios de la Unidad de Víctimas dedicados al trabajo de rehabilitación comunitaria. El uso de los términos tejedores y entrelazadores refleja una estrategia horizontal de construcción de lazos sociales a través de la superposición de participaciones y membresías de líderes y otros actores locales en diversas redes sociales y burocráticas que involucran trabajo en distintos aspectos del desarrollo comunitario.

De esta forma, construcción de paz hace referencia a un campo de teoría y práctica, reparación colectiva, a un mecanismo jurídico, y rehabilitación comunitaria, a las acciones orientadas a la recuperación del tejido social, las cuales también se han conceptualizado como unas de las cinco principales medidas de reparación para las víctimas en Colombia.

\section{Historias locales, capital social, resiliencia creativa y procesos participativos}

Aquí propongo que los proyectos musicales comunitarios en la comunidad de Libertad, los cuales surgen como prácticas de construcción de paz con potencial transformador, tienen un rol importante en la integración social de la comunidad. Estos proyectos han tenido impacto no sólo en la revitalización de prácticas culturales tradicionales, de esta manera recuperando importantes símbolos identitarios, así como fortaleciendo prácticas colectivas basadas en la empatía y la resiliencia, sino también articulando procesos de transformación de conflictos y rehabilitación del tejido social. En el caso de Libertad, este dinamismo se debe a los cuatro factores mencionados en la introducción de este artículo: 1) la relevancia histórica de las músicas festivas y participativas en las comunidades afrocolombianas, al menos desde el siglo XVII; 2) la existencia de múltiples niveles de capital social relacionado con las prácticas musicales locales; 3) la resiliencia de artistas y músicos locales al usar su capital cultural y creativo de manera consciente e ingeniosa con fines políticos; y 4) la estructura de programas institucionales que a veces facilita la participación comunitaria en los procesos de toma de decisiones.

$\mathrm{Al}$ reconocer que las prácticas musicales en Libertad han ayudado a mantener fuertes los lazos sociales por generaciones, mi planteamiento no es que usar la música para generar cohesión social es una práctica reciente, co-diseñada por líderes comunitarios e instituciones hegemónicas, sino que es una forma de expresión y acción sociocultural ancestral orientada a reunir a los miembros del grupo social a través de la celebración del patrimonio local y empoderando a los miembros de la comunidad para el desarrollo de iniciativas de orden solidario y colaborativo. Es lugar común en los trabajos sobre el Atlántico Negro dar un lugar histórico privilegiado al uso de prácticas musicales colectivas como estrategia común para adelantar acciones políticas y obtener concesiones, renegociando relaciones de poder, así como para adaptarse a entornos cambiantes (Monson 2004). La capacidad emancipatoria de algunas prácticas musicales afro-descendientes - refiriéndome por "emancipatoria" a su potencial para transformar la realidad social hacia condiciones más pacíficas y democráticas - ha existido históricamente en tensión con las agendas y planes de los grupos hegemónicos, y se ha transformado con ellos (Wade 2000, Guss 2000, Feldman 2006, Moore 2006, entre otros).

La historia de la región Caribe colombiana también muestra cómo las prácticas musicales afrocolombianas han funcionado desde antaño como mecanismos para la integración social, la reconstrucción de identidades, la solidificación de relaciones sociales y para crear espacios de resistencia ante la adversidad (Birenbaum 2009, Wade 2002, Bermúdez 1994). Estas prácticas han contribuido a dichos procesos a través de contextos participativos de performance, en los que se borran las distinciones binarias entre performante y audiencia; a través del uso intensivo del espacio público, actualizando y generando nuevos marcadores territoriales alrededor de las actividades musicales; demarcando ocasiones sociales importantes a través de las prácticas colectivas de música y danza; y a través de la integración social, la festividad y la alegría. Por esta razón, la práctica pública de estas músicas ha sido utilizada para resaltar momentos importantes y ha servido como estructura organizacional y espacio para la consolidación de lazos comunitarios, lo que ha llevado a que las autoridades las hayan considerado históricamente como agentes desestabilizadores del orden (Escobar 1985, cf. Sánchez 2009) y como un desafío a la naturaleza sistemáticamente racista y marginadora de los gobiernos nacionales (Rojas 2013: 55-83). Estos recursos culturales han permitido a los afrocolombianos relacionarse como agente colectivo más unificado y fuerte (aunque todavía marginal) ante los grupos de poder-como las autoridades coloniales, en el pasado, y el Estado colombiano, en el presente.

Sin creatividad ni resiliencia artística, ni siquiera los procesos históricos relevantes o la fortaleza actual del capital social serán suficientes para posicionar a la música como iniciativa dirigida a la construcción de paz. En el caso de Libertad, el colectivo artístico de jóvenes y grupo musical Afro-Música en los Montes de María, bajo el liderazgo de Luis Miguel Caraballo "Ralam" y con el apoyo de la sabedora 
Isabel Martínez "Chabelo", han sido resilientes y capaces de construir el capital social necesario para hacer avanzar este proyecto artístico y de desarrollo local. Después de la ocupación paramilitar, la actividad musical local era escasa, hasta que este grupo de jóvenes cantantes y compositores desarrollaron el bullenrap. Su proyecto tiene como misión la recuperación de las músicas tradicionales locales, sin dejar de practicar el hip-hop que gusta a los jóvenes, mezclándolo con lo tradicional, e incluyendo líricas de temas relacionados con el folclor, la cultura, las tradiciones y costumbres locales.

El exitoso proyecto musical dirigido por Ralam, el cual ha contado con el apoyo de Chabelo y distintas organizaciones en varios niveles, ha permitido el surgimiento de jóvenes líderes, despertando así nuevas formas de capital social multinivel. Sin embargo, es el talento social y artístico de este grupo de jóvenes, además de la calidad de su obra, cuidadosamente diseñada, lo que ayuda a generar contextos de empatía donde los miembros de esta comunidad comparten entre sí estados afectivos, agendas políticas e intereses en varios ámbitos. A través de esta resiliencia creativa, los músicos liberteños buscan soluciones para atender la fragilidad de las relaciones intergeneracionales dentro de la comunidad, permitiendo a los líderes más jóvenes enunciar sus preocupaciones y necesidades, y así participar de manera más directa y democrática en los diversos procesos de gobierno local, como el PIRC. En este sentido, un momento determinante ocurrió en abril de 2016, cuando se realizó una reunión entre la Unidad de Víctimas y el Comité de Impulso local al PIRC para discutir el proyecto de formación musical asociado al plan de reparación. En esta reunión, por primera vez, con entusiasmo y plena aceptación, Afro-Música hizo una presentación musical en la que la aprobación por parte de los líderes mayores fue unánime. Incluso, varios de ellos se pararon a bailar bullerengue, al son del bullenrap de estos jóvenes artistas.

El caso de Libertad también evidencia el impacto que el desarrollo participativo puede tener en grupos y comunidades proactivas. Fue por la naturaleza participativa del diseño del PIRC que se incluyeron programas que yuxtaponen la recuperación de las músicas tradicionales y otras expresiones populares y tradicionales con la rehabilitación de las relaciones intergeneracionales, uno de los principales daños al tejido social consecuencia de la ocupación. Sin embargo, la implementación de estos programas no siempre ha reflejado el mismo entusiasmo por los procesos participativos que si fue evidente en su fase de diseño. Por esto, muchas acciones estatales todavía pueden considerarse como paternalistas y asistencialistas y este enfoque desde arriba (top-down) sigue siendo el primordial. A pesar de esto, gracias a las "grietas de participación"-rupturas, luces, espacios a veces presentes en la implementación de proyectos, muchas veces ganados a pulso por la comunidad-los procesos culturales en el corregimiento de Libertad han ganado visibilidad en medios y han obtenido apoyo institucional y del sector sin ánimo de lucro. Sin embargo, dicho apoyo, en cifras, palidece en comparación con los presupuestos de proyectos de infraestructura, servicios públicos y desarrollo agrícola.

\section{Perspectivas culturalistas y desarrollistas sobre la(s) música(s) en Colombia}

Los proyectos de desarrollo en campos relacionados con las artes han basado sus enfoques en suposiciones acerca de la música que afectan directamente la política pública y el diseño de programas. Voy a abstraer las líneas principales de pensamiento y práctica en dos paradigmas: el enfoque "desarrollista" y el enfoque "culturalista." El enfoque desarrollista es de lejos el más prevalente y tiende a asumir que existen valores y significados universales y absolutos sobre la músi$\mathrm{ca}$, de manera supuestamente independiente de su contexto histórico y sociocultural, pero privilegiando valores y estéticas europeos y occidentales. Es común encontrar proyectos que utilizan estos estándares para guiar el camino que deben seguir las iniciativas musicales comunitarias: o bien tomando la forma del emprendimiento cultural, buscando acercar las prácticas locales a la industria musical como forma de desarrollo económico (Matarasso 1996: 13), o bien como programas de educación musical clásica, orientados al uso productivo del tiempo libre de la población joven (Mincultura 2005). Otro enfoque que ha sido común, ha sido la utilización de algunas formas de musicoterapia, por ejemplo, desde las cuales se ve la música como sonido clínico y puro, descontextualizado. De esta forma, no se tienen en cuenta procesos históricos y culturales de construcción de ideas sobre la música y la escucha aprendida (Dunn 2008).

En el enfoque desarrollista, las prácticas y tradiciones musicales más locales no se resaltan, en parte porque los funcionarios no piensan la música como una práctica social dentro de un contexto cultural distinto al suyo y, en cambio, la ven como parte, o del complejo de las "bellas artes," o como parte de las industrias culturales y del espectáculo. Las investigaciones sobre programas artísticos en el campo de los estudios sobre el desarrollo ponen en perspectiva el caso de Libertad, aportando casos que evidencian el rol de las artes en procesos de construcción de ciudadanía, mejorando condiciones de salud mental y generando redes de apoyo basadas en acciones de cooperación (Kay 2000, Guetzkow 2002, Sjollema y Hanley 2013). Este enfoque es relativamente reciente y defiende el valor de la evaluación cualitativa para determinar la contribución de las artes en contextos comunitarios. Esta perspectiva se opone a enfoques desarrollistas anteriores que concebían las artes como útiles solo para alcanzar indicadores cuantificables de desarrollo socioeconómico a través de, por ejemplo, el turismo o las industrias creativas. Sin embargo, son las metodologías cualitativas las que muchas veces reconocen las contribuciones del capital social y cultural al desarrollo socioeconómico (Matarasso 1996: 1-5). 
El enfoque culturalista, por otra parte, considera que la música es una práctica sociocultural que ha sido determinada históricamente, con sus significados imbuidos, cambiantes, emergentes y construidos a través de la interacción social (Cooley y Barz 2008). En línea con los enfoques posmodernos y poscoloniales sobre la cultura y la sociedad, algunos programas diseñados con enfoque culturalista entienden la música como práctica multicultural $\mathrm{y}$, con frecuencia, buscan desarrollar actividades colaborativas con actores locales para construir capacidades de liderazgo e identificar las necesidades que deben ser atendidas. Algunos programas culturales del Estado y la sociedad civil en la región Caribe también han tratado de fortalecer y reproducir contextos y prácticas sociales considerados "tradicionales" para la integración social, la intensificación de la sociabilidad y la interacción alegre y festiva, tales como las fiestas típicas de cada pueblo, posibilitando así el diálogo y la resolución de conflictos a través de las expresiones populares, posibilitando la construcción capital social y paz positiva.

En el enfoque culturalista, el reconocimiento a la diversidad es un presupuesto. En la política pública colombiana esto se encuentra, entre otros, bajo el nombre de "enfoque diferencial", el cual es obligatorio. Dicho enfoque busca dar cuenta de las necesidades y derechos específicos de ciertos grupos minoritarios y en estado de vulnerabilidad (grupos indígenas, otros grupos étnicos, población LGBTI+, mujeres, niños, adultos mayores, entre otros). Sin embargo, el enfoque diferencial no necesariamente implica un enfoque participativo que incluya miembros de las comunidades en los procesos de toma de decisiones, ni enfatiza la investigación basada en contextos sociales e históricos específicos. Las políticas de desarrollo participativo que acompañan iniciativas musicales locales siguen siendo casos raros en Colombia y sólo ahora están empezando a ser documentados por investigadores en otras partes del mundo (para casos de algunos países africanos, ver Odunuga 2013, Okpala 2015, Opiyo 2015).

Resulta fundamental, entonces, contemplar la idea de que "la música," sea lo que sea que se entienda por el término, no tiene inclinación, ni como sonido, ni como concepto, ni como práctica o comportamiento a ser moralmente "buena" o socialmente "constructiva," pues estas son todas ideas construidas al calor de la interacción social. A pesar de esto, la política pública, los discursos oficiales y los programas sociales sobre música tienden a asumir como cierto el supuesto de que la existencia de la música en sus planes y proyectos garantiza un impacto social positivo. Como se ha buscado analizar en este ensayo, dicho impacto es posible, pero únicamente si la música, sus prácticas relacionadas y las ideas con ellas asociadas se tienen en cuenta como fenómenos enmarcados en situaciones sociales, culturales e históricas concretas, específicas, pues esto permite desarrollar mecanismos de organización social alrededor de la música, creando canales para el empoderamiento de líderes culturales y facilitando sus acciones desde una orientación local y participativa hacia la transformación social. En este sentido, considerando la enorme diversidad de prácticas musicales locales en Colombia, no debería extrañarnos que más casos como el de Libertad - en el que las músicas locales son redefinidas con fines sociales específicos-salgan a la luz, tanto en zonas rurales como urbanas, ejemplificando las diversas maneras en que las prácticas culturales locales pueden jugar un papel importante en contextos de post-conflicto.

\section{Obras Citadas}

Arrázola, Roberto. 1970. Palenque, primer pueblo libre de América. Historia de las sublevaciones de los esclavos de Cartagena. Cartagena: Hernández Editores.

Bergh, Arild, y John Sloboda. 2010. "Music and Art in Conflict Transformation: A Review." Music and Arts in Action 2 (2): 2-18.

Bermúdez, Egberto. 1994. "Syncretism, Identity, and Creativity in Afro-Colombian Musical Traditions.” En Behague, 225-237.

Birenbaum Quintero, Michael. 2009. "Música afropacífica y autenticidad identitaria en la época de la etnodiversidad”. En Música y sociedad en Colombia. Translaciones, legitimaciones e identficaciones, editado por Mauricio Pardo, pp. 192216. Bogotá: Universidad del Rosario.

Cooley, Timothy J. and Gregory Barz (eds.). 2008. Shadows in the field: New perspectives for fieldwork in ethnomusicology. 2nd Edition. Oxford: Oxford University Press.

Cusick, Suzanne G. 2008. “Musicology, Torture, Repair.” Radical Musicology 3(1): 1-9.

Cusick, Suzanne. 2006. "Music as Torture / Music as Weapon.” Trans. Revista Transcultural de Música 10: 1-19. 
Dennis, Christopher. 2012. Afro-Colombian Hip-hop: Globalization, Transcultural Music, and Ethnic Identities. Plymouth (UK): Lexington Books.

De Granda, Germán. 1977. Estudio sobre un área dialectal hispanoamericana de población negra. Las tierras bajas occidentales de Colombia. Bogotá: Instituto Caro y Cuervo.

Dunn, Barbara M. 2008. Tranforming Conflict through Music. PhD Dissertation. Union Institute \& University. Cincinnati (OH).

Escobar, Luis Antonio. 1985. La Música En Cartagena De Indias. Recurso en línea: http://www.banrepcultural.org/blaavirtual/ musica/muscar/prohibe.htm. Recuperado: 19/7/2014.

Feldman, Heidi Carolyn. 2006. Black Rhythms of Peru: Reviving African Musical Heritage in the Black Pacific. Middletown, CT: Wesleyan University Press.

Forero, Juan. 2005. "New Colombia Law Grants Concessions to Paramilitaries". The New York Times. 23 de junio de 2005. Recurso en línea: https:/www.nytimes.com/2005/06/23/world/americas/new-colombia-law-grants-concessions-toparamilitaries.html. Recuperado 16/4/2019.

Galtung, Johan. 2008. "Peace, Music, and the Arts: In Search Of Interconnections." En Urbain, Olivier, ed. 2008. Music and Conflict Transformation: Harmonies and Dissonances in Geopolitics. IB Tauris. 53-60.

Galtung, Johan. 2000. Conflict Transformation by Peaceful Means. Sage.

García Caraballo, Apolinar. Ca. 2012. Crónicas de la Historia y el Origen de un Pueblo. Este Pueblo se llama Libertad y por eso no tiene Iglesia. Libro inédito.

George, Nelson. 2004. "Hip-Hop's Founding Fathers Speak the Truth". En, That's the joint! The hip-hop studies reader, editado por Mark Anthony Neal y Murray Forman. New York: Routledge.

Guetzkow, Joshua. 2002. "How the Arts Impact Communities: An introduction to the literature on arts impact studies." Taking the Measure of Culture Conference. Princeton University, June 7-8, 2002.

Guss, David M. 2000. The Festive State: Race, Ethnicity, and Nationalism as Cultural Performance. Berkeley: University of California Press.

Kartomi, Margaret. 2010. "Toward a Methodology of War and Peace Studies in Ethnomusicology: The Case of Aceh, 19762009.” Ethnomusicology 54(3): 452- 483.

Kay, Alan. 2000. "Art and Community Development: The Role the Arts have in Regenerating Communities." Community Development Journal 34 (5): 414-424.

Kent, George. 2008. "Unpeaceful music." En Urbain, Olivier, ed. 2008. Music and Conflict Transformation: Harmonies and Dissonances in Geopolitics. IB Tauris. 104-111.

List, George. 2017. Animal Tales from the Caribbean (póstumo). Editado por John McDowell y Juan Sebastián Rojas. Bloomington: Indiana University Press.

McDonald, David A. 2013. My Voice Is My Weapon: Music. Nationalism, and the Poetics of Palestinian Resistance. Durham: Duke University Press.

McMillan, David. 1976. Sense of community: An attempt at definition. Unpublished manuscript. George Peabody College for Teachers, Nashville, TN.

McMillan, David y David Chavis. 1986. "Sense of Community: A Definition and Theory." Journal of Community Psychology 14: 6-23. 
Matarasso, Francois. 1996. "Defining Values: Evaluating Arts Programmes.” Working paper. Glasgow: Comedia.

Ministerio De Cultura De Colombia (Mincultura). 2005. Manual para la Gestión de Bandas-Escuelas de Música. Bogotá: Plan Nacional de Música para la Convivencia.

Monson, Ingrid. 2004. The African Diaspora: A Musical Perspective. Music Library Association.

Moore, Robin. 2006. Music and Revolution: Cultural Change in Socialist Cuba. University of California Press.

Motley, Carol y Rosa Henderson. 2008. "The global hip-hop Diaspora: Understanding the culture". Journal of Business Research 61 (3). Revisado 20/04/2019. URL: https://doi.org/10.1016/j.jbusres.2007.06.020

Muñoz, Laura Juliana. 2010. “Experto critica escasos avances en Ley de Justicia y Paz”. El Espectador. 15 de febrero de 2010. Recurso en línea: https://www.elespectador.com/impreso/temadeldia/articuloimpreso187949-experto-critica-escasosavances-ley-de-justicia-y-paz. Recuperado 18/4/2019.

Navarrete, María Cristina. 2012. “Celebraciones para la vida y la muerte. Carnestolengos en Cartagena de Indias”. Huellas 7175: 139-143. Uninorte: Barranquilla.

O’Connell, John Morgan. 2010. “Introduction: An Ethnomusicological Approach to Music and Conflict.” In O'Connell and Castelo-Branco, 1-14.

O’Connell, John Morgan, y Salwa El-Shawan Castelo-Branco, eds. 2010. Music and Conflict. Champaign: University of Illinois Press.

Odunuga, A. Funmilayo. 2013. "Preventing Socio-Political Conflicts and Building Peace Block: The Role of Music." Mediterranean Journal of Social Sciences 4 (2): 703- 708.

Okpala, Nkechi H. 2015. "The Place of Igbo Folk Songs in Peace Building and Sustainable Rural Development." International Journal of Arts and Humanities (IJAH) 4(3): 200-207.

Opiyo, Lindsay McClain. 2015. "Music as Education, Voice, Memory, and Healing: Community Views on the Roles of Music in Conflict Transformation in Northern Uganda." African Conflict and Peacebuilding Review 5(1): 41-65.

Organización de las Naciones Unidas para la Migración (OIM). 2012a. Del Daño a la Reparación Colectiva. Bogotá: USAID.

Organización de las Naciones Unidas para la Migración (OIM). 2012b. "Proceso de Reparación Colectiva. Comunidad de Libertad”. Bogotá: USAID.

Pettan, Svanibor. 2008. "Applied Ethnomusicology and Empowerment Strategies: Views from across the Atlantic.” MuzikološKi Zbornik - Musicological Annual 64(1): 85- 99.

Rojas, Juan Sebastián. 2013. From street Parrandas to folkloric festivals: The institutionalization of Bullerengue music in the Colombian Uraba region. MA Thesis, Indiana University Bloomington. ProQuest Open Access.

Rojas, Juan Sebastián y John McDowell. 2017. “Editors’ Introductory Essay”. En, George List, Animal Tales from the Caribbean.

Rosenfeld, Friederich. 2010. "Collective Reparation for Victims of Armed Conflict." International Review of the Red Cross 92(879): 731-746.

Sánchez, Hugues. 2009. "De Bundes, Cumbiambas y Merengues Vallenatos: Fusiones, Cambios y Permanencias en la Música y Danzas en el Magdalena Grande, 1750- 1970”. En Música y sociedad en Colombia. Translaciones, legitimaciones e identficaciones, editado por Mauricio Pardo, pp. 80-99. Bogotá: Universidad del Rosario. 
Sandoval, Elaine. 2016. "Music in Peacebuilding: A Critical Literature Review.” Journal of Peace Education 13 (3):200-217.

Sjollema D. Sandra y Jill Hanley. 2013. "When words arrive: A qualitative study of poetry as a community development tool." Community Development Journal 49 (1): 1-15.

Urbain, Olivier, ed. 2008. Music and Conflict Transformation: Harmonies and Dissonances in Geopolitics. IB Tauris.

Wade, Peter. 2002. "Construcciones de lo negro y de África en Colombia. Política y cultura en la música costeña y el rap". En Afrodescendientes en las Américas. Trayectorias sociales e identitarias. 150 años de la esclavitud en Colombia, editado por Claudia Mosquera, Mauricio Pardo y Odile Hoffman. Bogotá: Universidad Nacional de Colombia, 245-278.

Wade, Peter. 2000. Music, Race, and Nation: Musica Tropical in Colombia. Chicago: Chicago University Press.

\author{
Apéndice
}

\title{
La marucha
}
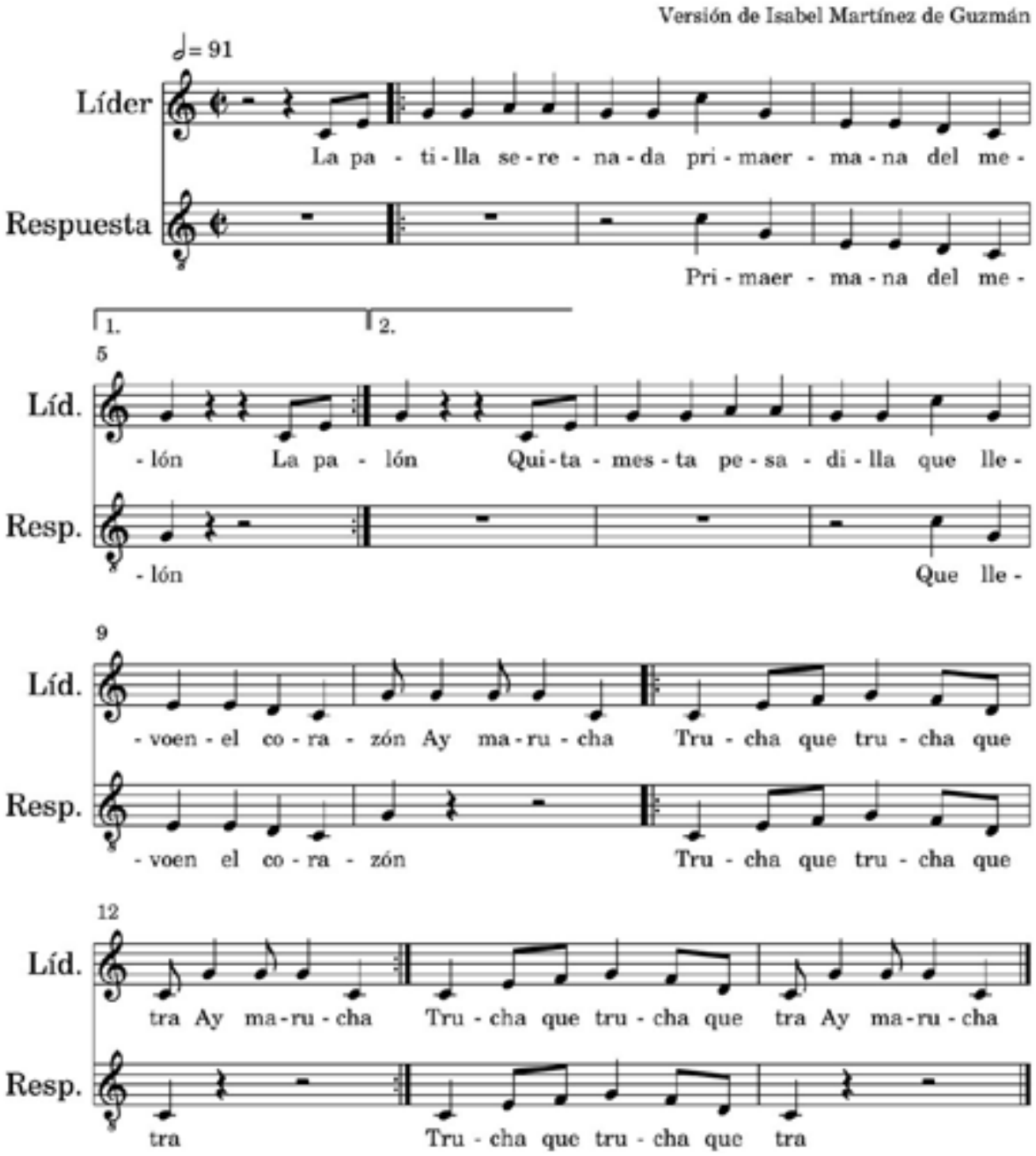


\section{A pie pelao (estribillo)}

Afro-Música en los Montes de María $d=89$

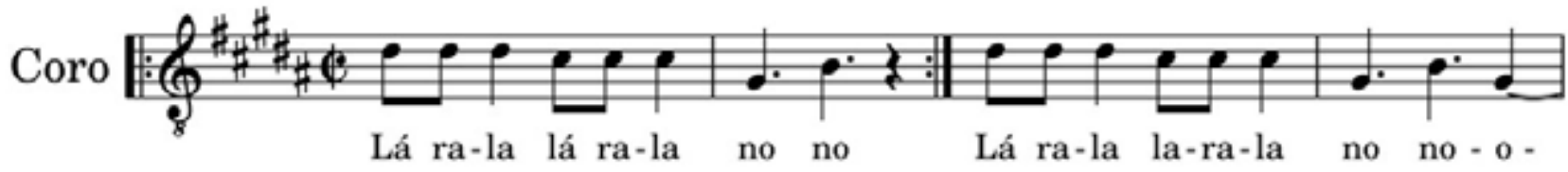

5

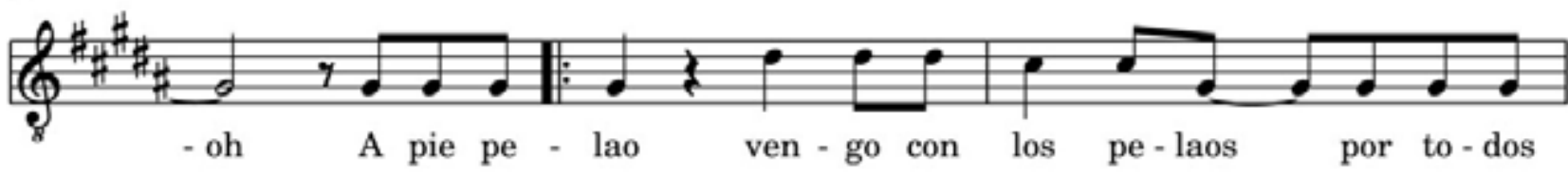

8

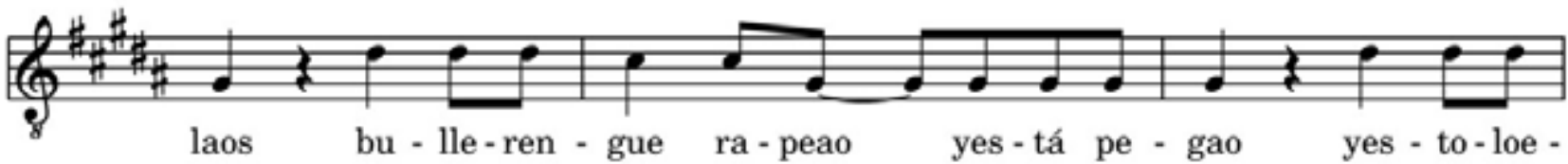

11

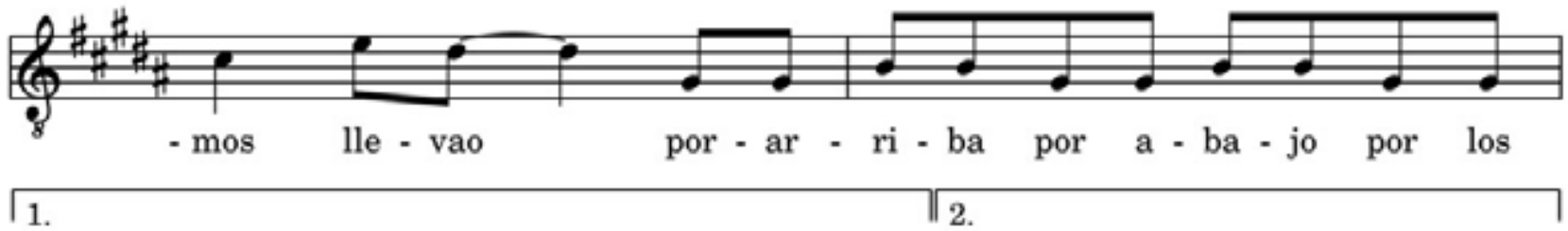

13

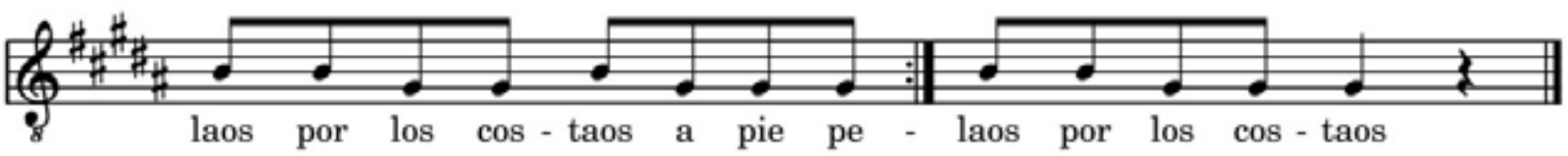




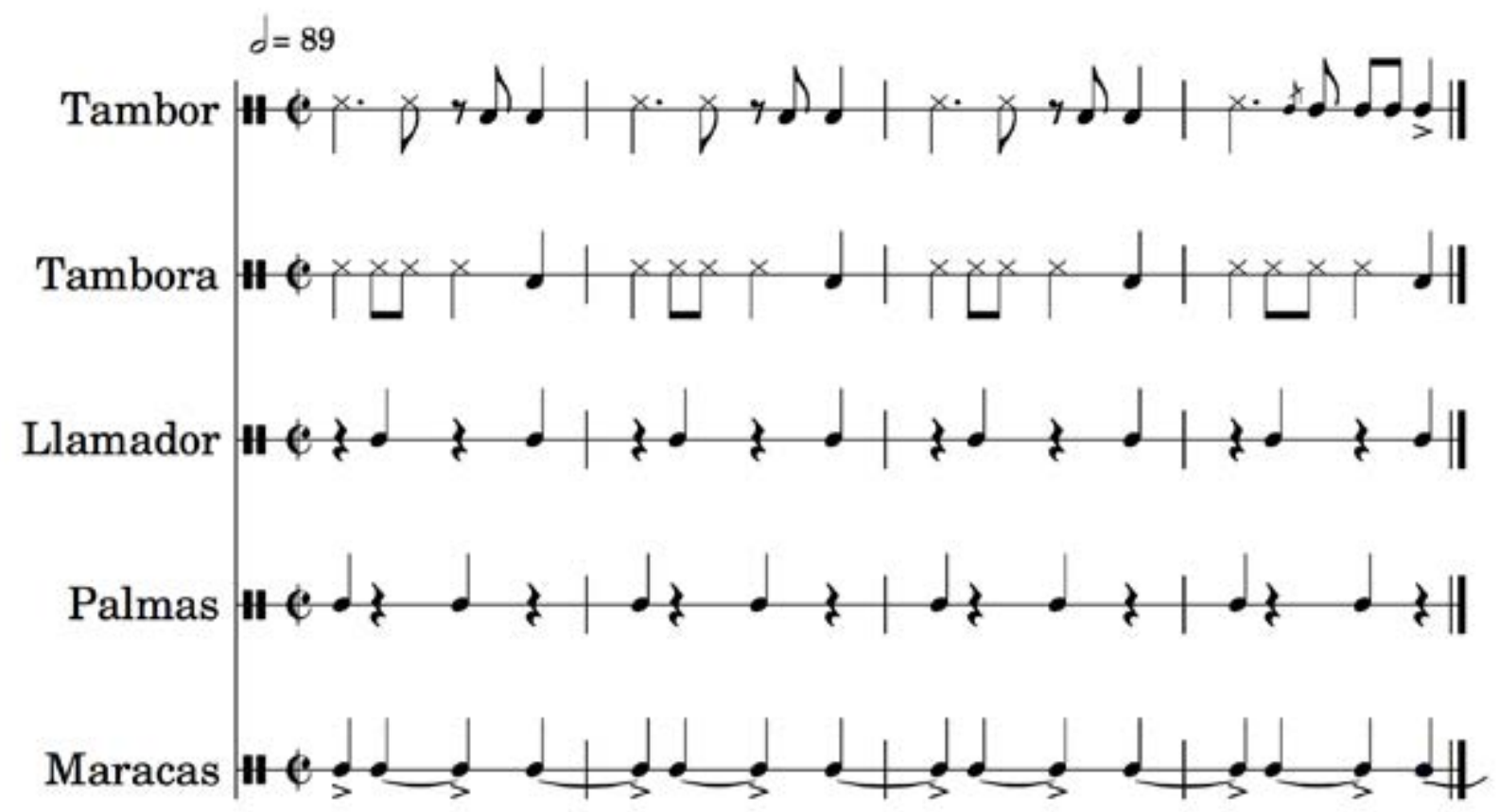

Notas

1. Este artículo está basado en secciones de mi tesis doctoral, publicada por el Departamento de Folklore y Etnomusicología de la Universidad de Indiana, Bloomington (2018).

2. No confundir con el periodo de intensa violencia bipartidista de mediados del siglo XX a nivel nacional, consecuencia del asesinato de Jorge Eliécer Gaitán en Bogotá, y al cual suelen referirse los historiadores como La Violencia.

3. La versión de "La marucha" que aquí transcribo fue tomada de una grabación hecha a la maestra de juegos de velorio Isabel Martínez, de Libertad, durante un velorio en marzo de 2016.

4. Transcripción de una grabación hecha por mí en Libertad, en noviembre de 2015, durante un ensayo de Afro-Música.

5. A través de 33 encuestas realizadas en todos los barrios de Libertad a habitantes no vinculados directamente con procesos musicales, encontré que, si bien las músicas de tambores hoy en día gozan de una imagen positiva, las músicas relacionadas con los picó, como la champeta y el reguetón, suelen estar más asociadas a actividades socialmente condenadas como las peleas y las infidelidades de pareja. 